

\section{Erotismo e o mundo pop: o stimmung e a nudez de Marge Simpson na revista Playboy}

\author{
Eroticism and the pop world: \\ the stimmung and Marge Simpson's \\ nudity in Playboy
}

\section{Rodrigo Rodembusch ${ }^{1}$}

\section{Resumo}

O imaginário masculino ganhou novos contornos e dimensões com o desenvolvimento da tecnologia e o cruzamento de mídias. Em 2009, a convergência de duas realidades marcou uma das publicações mais iconográficas do mercado erótico adulto: a nudez da personagem de desenho animado Marge Simpson na Playboy americana. Assim, este artigo busca refletir, a partir da experiência estética da matriarca do clã de Os Simpsons, o conceito de stimmung. Buscarei perspectivar este evento a partir dos estudos de Gumbrecht (2006 e 2014), Preciado (2010) e Silveira (2014).

\section{Palavras-chave}

Stimmung; fotografia; Os Simpsons; Playboy.

\section{Abstract}

The male imaginary gained new contours and dimensions with the development of technology and the intersection of different media. In 2009, the convergence of two realities marked one of the most iconographic publications of the erotic adult market: the nudity of the cartoon character Marge Simpson in the cover of Playboy. Thus, this article aims to reflect, from the aesthetic experience of the matriarch of The Simpsons clan, the concept of stimmung from Gumbrecht studies (2006 and 2014), Preciado (2010) and Silveira (2014).

\section{Keywords}

Stimmung; photography; The Simpsons; Playboy. 


\section{Introdução}

O ano é 2009, o mês, outubro, o dia, 16. Nas bancas de revistas, a Playboy, uma das publicações mais conhecidas do público masculino (e por que não do feminino também) traz em sua capa Marge Simpson, esposa de Homer Simpson, personagens da série mais longa da televisão americana, que foi ao ar pela primeira vez em 17 de dezembro de $1989^{2}$. A intenção era celebrar os 20 anos da franquia - com um ensaio sensual da matriarca da família Simpson. Uma celebridade que extrapola a realidade de carne e osso das capas da revista, mas que para frequentar as páginas ganhou contornos inerentes ao estereótipo feminino. Para manter a atmosfera de realidade, a edição contou ainda com uma entrevista e uma ficha com informações sobre Marge, o que é de praxe entre as beldades que se despem para a Playboy americana. Conforme Benjamin (1985), "o homem tem a capacidade suprema de produzir semelhanças". Esta observação cabe ao exercício aqui proposto, uma vez que este foi o intuito da revista: replicar características que remetessem ao universo tipicamente erótico de Playboy, mesmo que na capa, a figura feminina escolhida não fosse humana.

Assim, a escolha de uma personagem de desenho animado como uma coelhinha da Playboy abre um leque de possíveis reflexões acerca do ineditismo da ação e da experiência estética ali representada, sem mencionar a intenção de alavancar o mercado, que vê paulatinamente o declínio do número de exemplares vendidos desde 2006 - de 3,15 milhões para 2,6 milhões ${ }^{3}$.

É a partir deste evento que busco, neste artigo, discutir o conceito de stimmung, do alemão Hans UIrich Gumbrecht perspectivando o objeto Marge na Playboy, bem como trazer também à discussão os estudos de Beatriz Preciado e a representação do erótico feminino na publicação masculina.

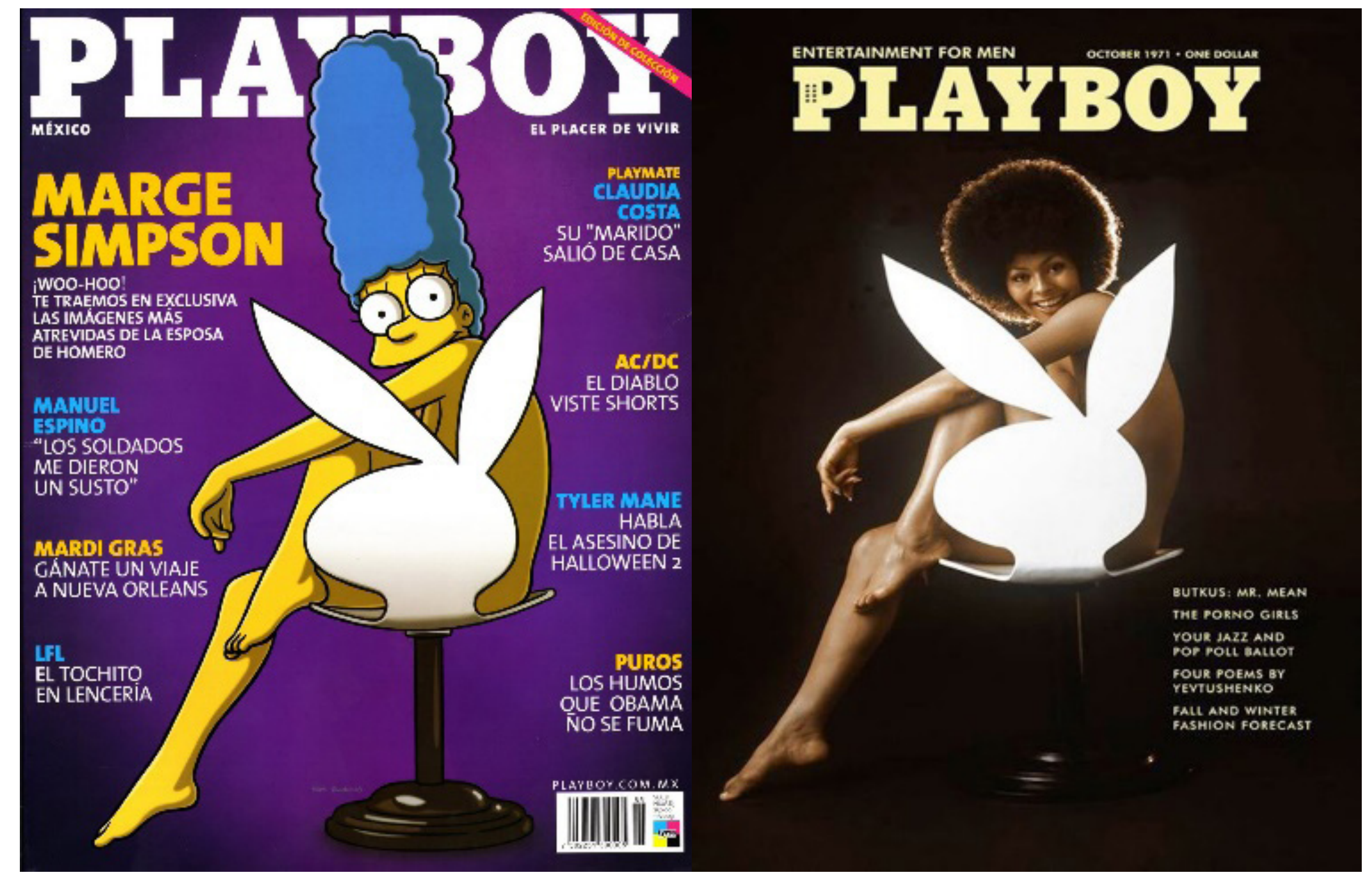

Figura 1 - Capa da revista Playboy de outubro de 2009.

\section{A Playboy e a nudez}

de Marge Simpson

A franquia Playboy transformou o universo masculino e a indústria do entretenimento adulto. Apesar de não ser o escopo deste artigo fazer uma arqueologia da publicação, é importante destacar as tendências e a objetificação sexual feminina oriundas de suas páginas, que farão parte da reflexão aqui proposta. Nos Estados Unidos, a primeira edição ocorreu em 1953 e três anos mais tarde, foi publicado o primeiro pôster na página central, com Marian Stafford ${ }^{4}$.

Conforme Silveira (2014), a Playboy "irá instruir e modelar as novas dimensões do afeto, do desejo e das práticas sexuais que virão à tona, que serão reguladas e convertidas em capital-imagem ao longo da segunda metade do século passado". Nos anos 60, o Playboy Club foi inaugurado em Chicago e a franquia expandiu nas décadas seguintes. Preciado (2010) destaca que o conceito Playboy representou uma alter-

109 PORTO ALEGRE | v. 20 | n. 34 | 2015 | pp. 108-112 Sessōes do Imaginário 
nativa extrema para o modo de vida dos anos 50 , um contra-espaço desafiador.

Entre as estrelas que desfilaram na publicação estão Sophia Loren (1957), Elizabeth Taylor (1963), Jane Fonda (1966), Farrah Fawcett (1978), Cindy Crawford (1988) e Sharon Stone (1990). Todas elas, mulheres que habitaram o imaginário masculino. Nos anos 2000, um evento marcou a história da Playboy: a tradicional revista apresentou uma personagem de desenho animado para ilustrar sua capa em outubro de 2009 (Figura 1). Esta foi a primeira vez que a coelhinha do mês não era uma representante do gênero feminino de carne e osso.

Parafraseando Silveira (2014) ao afirmar que "quase trinta e dois anos depois de Marylin Monroe, é Madonna quem exibe a boa forma, o físico esculpido nas páginas da revista, para milhões de assinantes", agora é a vez de, pela primeira vez em sua história, a publicação americana dar espaço a Marge Simpson, que exibe a boa forma, o físico esculpido para os assinantes - formas e medidas diferentes das apresentadas nos episódios de Os Simpsons.

A pose escolhida de Marge é uma cópia literal de uma capa de 1971, que também teve uma característica inédita para a Playboy: uma modelo afrodescendente e uma impressionante cabeleira, como a de Marge $^{5}$.

Dentro da edição, a personagem do desenho animado ganhou outras páginas, inclusive as centrais, espaço nobre da publicação (Figuras 2 e 3).

A capa da Playboy com a personagem Marge Simpson suscita uma discussão quanto à presença do stimmung, conceito que não contou como primeiro propositor Hans Ulrich Gumbrecht, mas que teve no alemão um grande entusiasta em estudá-lo. Porém, antes de passarmos para esta análise, é importante trazer à tona a definição de pornografia de Preciado (2010), que serve sobremaneira para este estudo: nuevas, prácticas de consumo de la imagen suscitadas por nuevas técnicas de reproducción y distribuición y, de paso, codificar um conjunto de relaciones inéditas entre imagen, placer, publicidade, privacidade y producción de subjetividade.

A partir da conceituação proposta pela autora, a revista Playboy habita o universo da pornografia e, por consequência, Marge, como experiência estética, faz parte desta realidade porno-erótica. Para Gumbrecht (2006) um objeto qualquer ao ganhar alguma forma de atenção diferenciada, pode caracteriza-se como uma experiência estética. No caso específico deste artigo, uma capa diferente do normal é uma interrupção, isto é, uma quebra no fluxo considerado cotidiano, logo, uma experiência estética. Segundo o filósofo alemão, desse processo são produzidas "pequenas crises".

Especificamente sobre a capa inédita da edição de 2009, Gumbrecht destaca que "o componente cotidiano é dado por um plano situacional primário em certas práticas e certos comportamentos acontecem

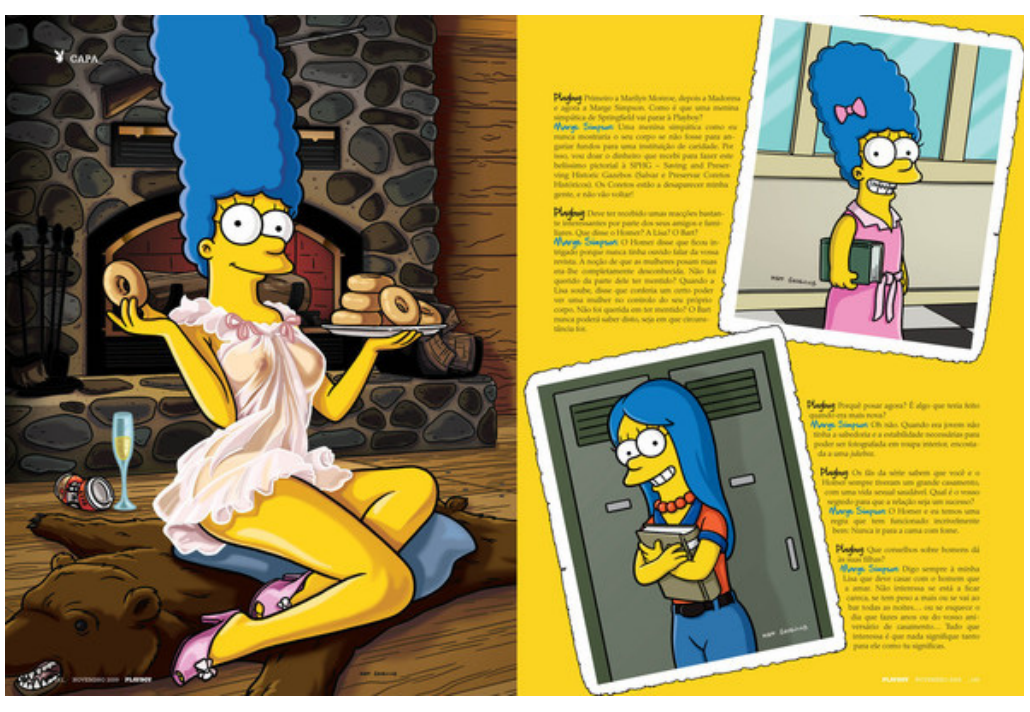

Figura 2 - Foto sensual de Marge Simpson e entrevista - parte 1 normalmente" (2006, p. 59). Isso quer dizer que o normal seria apresentar na capa da Playboy mulheres reais, o que não ocorreu. $A$ ausência do comum ou a presença do incomum nos oferece um outro nível de análise: o do stimmung.

\section{O stimmung de Gumbrecht}

O conceito de stimmung atravessou a história no pensamento de diversos autores. Para este trabalho nos interessa os estudos de Gumbrecht, que considera a "palavra alemã muito difícil de traduzir" (2014, p. 11). O autor segue afirmando que "para podermos ter consciência e perceber o valor dos diferentes sentidos e das nuances de sentido invocados pelo stimmung, será útil pensar nos conjuntos de palavras que servem para traduzir o termo em algumas línguas" (2014, p. 12). É na soma dos diversos significados que o conceito é construído. O dicionário alemão Langenscheidt apresenta, por exemplo, as seguintes traduções para stimmung: atmosfera, humor, temperamento, disposição, sentimen-

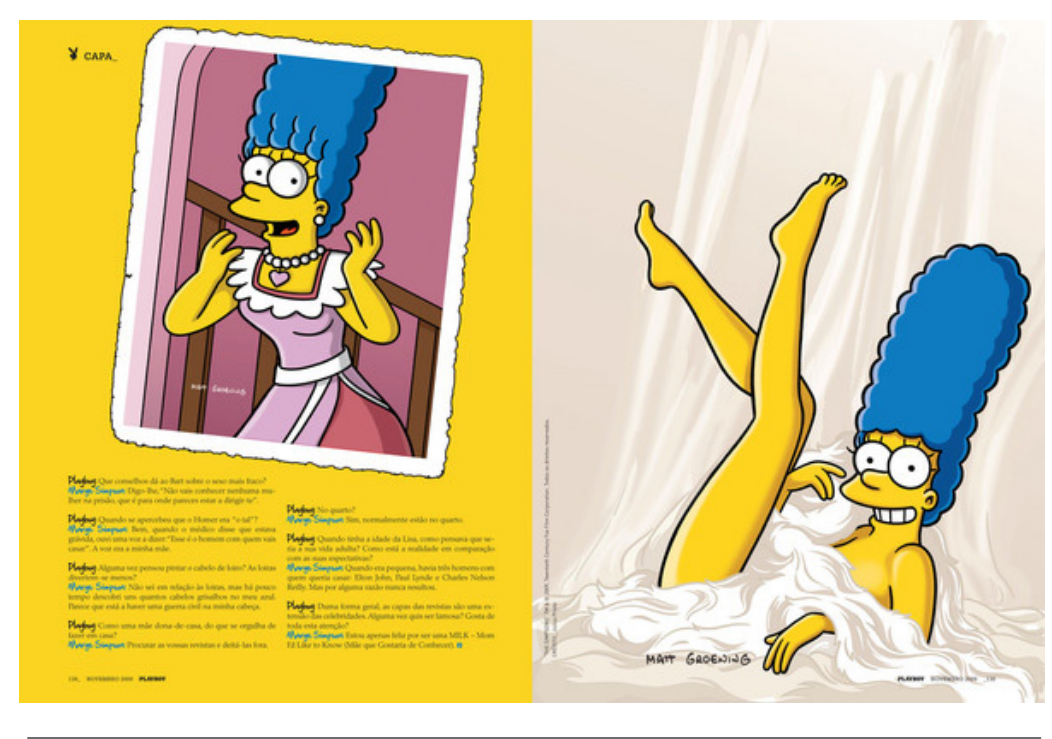

Figura 3 - Foto sensual de Marge Simpson e entrevista - parte 2.

110 PORTO ALEGRE | v. 20 | n. 34 | 2015 | pp. 108-112 Sessões do Imaginário 


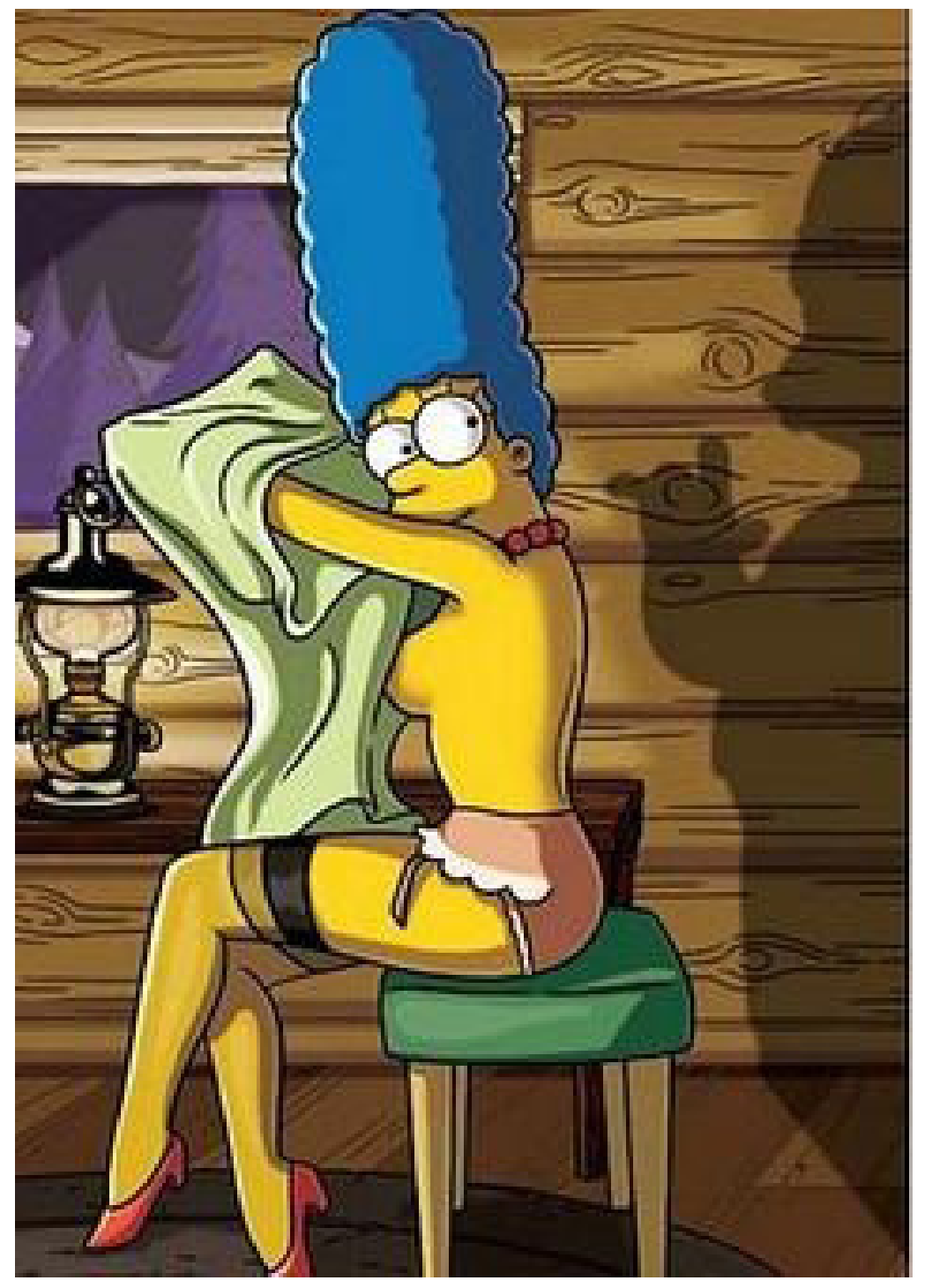

Figura 4 -Marge Simpson ganha curvas sensuais na publicação

to e espírito - cada uma variando conforme o contexto em que são empregadas.

Ainda na mesma linha de raciocínio, fica claro compreender Heiddegger que se refere a um misto de "medo e ira, esperança e alegria, entusiasmo, ânimo e tédio" (2014, p. 119). Nessa perspectiva, é tão amplo o espectro do stimmung, que ele poderia ser compreendido como uma sensação que um objeto, neste caso, a capa da revista Playboy de outubro de 2009, traz a quem a contempla.

Para corroborar com essa ideia, Gumbrecht afirma que "hoje não existe situação sem sua atmosfera própria, sem seu ambiente próprio, o que significa que é possível procurarmos o stimmung característico de cada situação, obra ou texto" (2014, p. 20). Mesmo assim, é impossível determinar os elementos que constituem o stimmung. Em outras palavras, não se pode isolar cada componente do stimmung. Ele é soma, não subtração. É protagonismo e antagonismo ao mesmo tempo.

Dentro da análise proposta neste artigo, a compreensão do conceito de "habituação" (2014, p. 31) se faz necessária. Para Gumbrecht, quando a presença do stimmung se concretiza é porque ocorreu uma "experiência primária, ao ponto de tornar-se reflexo pré-consciente" (2014, p. 31). No caso da capa da revista Playboy com Marge Simpson, a habituação e o pré-consciente podem ser entendidos como a própria ambiência e atmosfera que a publicação traz consigo ao longo dos anos.

Elementos como o coelho símbolo da franquia - que dá forma à cadeira (ver Figura 1), a nudez feminina e a palavra Playboy remetem a um universo específico: o do entretenimento erótico adulto de qualidade. É um objeto com um ur-stimmung ${ }^{6}$. E para corresponder a estas expectativas primeiras oriundas da revista, Marge ganhou contornos femininos característicos das mulheres retratadas pela Playboy (Figura 4).

Na reflexão aqui proposta, fica claro que a revista Playboy, ao longo de sua existência, criou ao seu redor uma atmosfera, uma ambiência, i.e., um stimmung que precisa ser correspondido e revivido a cada nova edição. Nada mais natural que Marge Simpson recebesse tal tratamento, como pode ser percebido nas imagens apresentadas neste artigo: mais curvilínea, inclusive com os seios à mostra (ver Figura 2). É o ur-stimmung determinando como o objeto a ser representado deve ser construído. Para embasar essa perspectiva, Gumbrecht lembra de como o stimmung "existencial da juventude que passou" se mantém vivo na voz de Janis Joplin (2014).

A capa da Playboy também mantém vivo um emaranhado de sensações e experiências, mesmo que seja uma personagem de desenho animado a figura feminina de destaque. Apesar de não haver uma pesquisa qualitativa acerca da sensação do público quanto à ausência de uma mulher de carne e osso na edição de outubro de 2009, é possível imaginar que todo o stimmung inerente à franquia/revista tem um papel importante na aceitação de Marge Simpson como coelhinha do mês.

Seguindo a análise, se os textos agem sobre os "estados de espírito" dos leitores da mesma maneira que o clima atmosférico e a música (Gumbrecht, 2014) é possível relacionar o mesmo raciocínio com a capa de Marge Simpson. No objeto de estudo deste artigo, a imagem (ver Figura 1) mexe com o imaginário do leitor porque o stimmung da revista assim o propicia, mesmo que se trate de uma personagem de desenho animado. Esta afirmação tem como base o pensamento de Gumbrecht, ao destacar que há características materiais nas obras que acabam por traduzir o stimmung, mesmo que "tendo em conta o número potencialmente ilimitado de perspectivas, para cada objeto pode existir uma série infinita de interpretações e de modos de encontro. (2014).

Em resumo, a construção de uma memória via sensação causada pela experiência de pensar na materia- 
lidade do objeto Playboy é fundamental para compreender a existência e as implicações do stimmung de Gumbrecht. Tratar de stimmung suscitaria, sem dúvida, também a abordagem da aura benjaminiana e a questão da autenticidade - um estudo deveras interessante de comparação, mas que não é escopo deste artigo.

\section{Considerações finais}

A franquia Playboy, ao longo de sua existência determinou profundas alterações no modo de consumo do erótico, além de ter um papel fundamental na mudança de perspectiva de espaços considerados tradicionais, conforme mostrou Preciado. A publicação, criada em 1953, apresentou a mulher como nunca antes, definindo um estereótipo feminino e criando uma aura ao redor da revista. Falar em Playboy implica em uma série de sensações, memórias e expectativas, elementos que têm relação direta com o stimmung de Gumbrecht. A palavra reúne diversos significados e é carregada de uma forte carga histórica. Ela existe, mas não é tátil. Está no nível da percepção, da experiência pessoal. Para finalizar, fica muito claro que o stimmung "está lá", basta ser acessado e para tal é necessário, entre outros gatilhos, a existência primária.

Este artigo é finalizado com uma reflexão de Gumbrecht, que acredita que o papel do intelectual é deixar o mundo mais complexo, já que não existe a obrigação de apresentar soluções para os questionamentos propostos. Portanto, a pergunta permanece: afinal de contas, o que é stimmung?

\section{Referências}

BENJAMIN, Walter. A doutrina nas semelhanças. In: Magia e técnica, arte e política. São Paulo: Editora Brasiliense, 1985.
GUMBRECHT, Hans Ulrich. Atmosfera, ambiência, Stimmung: sobre o potencial oculto da literatura. Rio de Janeiro: Editora PUC Rio, 2014.

Pequenas crises: Experiência estética nos mundos cotidianos. In: GUIMARÃES, César; LEAL, Bruno; MENDONÇA, Carlos Camargo (orgs.). Comunicação e experiência estética. Belo Horizonte: Editora UFMG, 2006.

PRECIADO, Beatriz. La Mansión Playboy: la invención del burdel multimídia. In: PRECIADO, Beatriz. Pornotopia. Arquitectura y sexualidad em Playboy durante la Guerra Fria. Barcelona: Editorial Anagrama, 2010.

Pornotopia. Arquitectura y sexualidad em Playboy durante la Guerra Fria. Barcelona: Editorial Anagrama, 2010.

SILVEIRA, Fabrício. Além da atribuição de sentido. Verso e Reverso. São Leopoldo: Unisinos, 2010, pp. 183-186.

The Punk Embodiment. Madonna + Riot

Grrrls + Genesis P-Orridge. Comunicação apresentada durante o XI Congresso da Associação Internacional para os Estudos da Música Popular - América Latina, ocorrido na Universidade Federal da Bahia/UFBA, em Salvador, 2014.

Notas

1 Doutorando em Ciências da Comunicação na Unisinos. Professor na Faculdade de Comunicação Social do Centro Universitário Ritter dos Reis (Rua Orfanotrófio 555, Alto Teresópolis, Porto Alegre/RS, Brasil, CEP: 90840-440). E-mail: r.rodembusch@gmail.com.
2 Fonte: http://veja.abril.com.br/noticia/entretenimento/ fotos-marge-simpson-playboy. Acesso em: 20 de dez. 2014.

3 Fonte: http://usatoday30.usatoday.com/life/television/ news/2009-10-09-simpson-playboy_N.htm. Acesso em: 20 dez. 2014.

4 Fonte: http://mundodasmarcas.blogspot.com. br/2006/05/playboy-o-prazer-masculino.html. Acesso em: 21 dez. 2014.

5 Fonte: http://usatoday30.usatoday.com/life/television/ news/2009-10-09-simpson-playboy_N.htm. Acesso em: 20 dez. 2014.

6 Me refiro à partícula Ur (em alemão), que indica algo ancestral, que antecede, que existe antes mesmo do objeto material existir. No caso deste artigo, falar em Playboy já traz o stimmung que envolve a publicação, mesmo que não haja um contato físico, uma experiência material com a mesma. A experiência acontece em um nível subconsciente. 